\title{
External fixation as a primary and definitive treatment for tibial diaphyseal fractures
}

\author{
Michail Beltsios · Olga Savvidou · John Kovanis · \\ Panagiotis Alexandropoulos $\cdot$ Panagiotis Papagelopoulos
}

Received: 9 February 2009/Accepted: 4 August 2009/Published online: 28 August 2009

(C) Springer-Verlag 2009

\begin{abstract}
The aim of this study was to evaluate the effectiveness of unilateral external fixator as primary and definitive treatment for open tibial fractures, fractures with severe soft tissues injuries, threatened compartment syndrome, and in multiply injured patients. Two hundred and twenty-three tibial shaft fractures (212 patients) were treated. In open fractures, union was achieved in 25 weeks, while in closed in 21 . There were 18 nonunions, 21 delayed unions, 4 malunions, 58 pin infections and 3 osteomyelitis. A reoperation was performed in 42 patients. Fat embolism was diagnosed in three patients, pulmonary embolism in five and deep venous thrombosis in 14 . The external fixator was definitive treatment in $87.27 \%$. Unilateral external fixators can be used as primary and definitive treatment for complicated tibia shaft fractures. Re-operation or change of the method must be performed only when there is a delay in callus formation.
\end{abstract}

Keywords External fixation - Definitive treatment . Open tibial fractures - Threatened compartment .

Syndrome $\cdot$ Multiply injured patients

M. Beltsios · O. Savvidou - J. Kovanis · P. Alexandropoulos · P. Papagelopoulos

Orthopaedic Department, General Hospital of Elefsis,

«Thriassio», Leoforos Gennimata, Magoula,

19600 Athens, Greece

M. Beltsios ( $\square)$

Hanion 1, 11257 Athens, Greece

e-mail: mpelmi@gmail.com

\section{Introduction}

Intramedullary (IM) nailing is considered the method of choice for treatment of closed diaphyseal fractures of the tibia. However, there is controversy in the literature regarding the best way of managing open type III fractures, tibial shaft fractures with severe soft tissue injuries or compartment syndrome, and tibial fractures in multiply injured patients. It has yet to be determined whether angle-stable (locking) plate fixation, primary IM nailing, primary external fixation followed by conversion to IM nailing, or external fixation as definitive treatment is the ideal surgical management for these types of tibial shaft fractures. External fixation was widely used in the early part of the 20th century but fell into disregard later with advent of new internal fixation devices. Its use was popular again in the 1980s but there were still a number of questions and problems with its use. Furthermore, there has been considerable debate over the optimal frame design and biomechanical characteristics of different fixators.

The purpose of this retrospective study was to evaluate the results and effectiveness of an unilateral external fixator (EBI or Orthofix) as a primary and definitive treatment for the above examples of high risk injuries.

\section{Patients and methods}

Two hundred and twelve patients (223 tibia shaft fractures) who were treated with unilateral external fixators and followed by the authors over the last decade are included in this study. The external fixators were either Orthofix (Orthofix Inc.) or EBI (Biomet Inc.) using stainless steel half pins. The inclusion criteria for application of the external fixators were 
1. severe soft tissues injuries in 26 fractures,

2. impending compartment syndrome in 30 fractures,

3. Gustilo type III open fractures in 139 cases, and

4. 28 fractures in multiply injured patients.

\section{Exclusion criteria were}

1. fractures with bone defects,

2. a concomitant fracture of the femur, and

3. intra-articular fractures.

The mean patients' age at the time of the injury was 36 years (range 15-80 years). There were 170 male and 42 female patients. One hundred and sixty-two patients were injured in motor vehicle accidents and the remaining 50 injured in falls from a height. The mean time from the accident to surgery was $10 \mathrm{~h}$.

The fracture patterns were categorized according to the $\mathrm{AO} / \mathrm{ASIF}$ classification: there were 110 type A fractures, 77 type $\mathrm{B}$, and 36 type $\mathrm{C}$. A radiolucent table was used and fracture reduction was checked intraoperatively with fluoroscopy. In 45 fractures a traction table with calcaneal pin traction was used to facilitate reduction. Our intention was to achieve an anatomical closed reduction including axial and side-to-side compression. Open fractures were managed by primary soft tissue cover of vessels, nerves, tendon and bone. Autologous iliac bone graft was used in nonunions.

The patients were encouraged early movement of the knee and ankle joints and muscular exercises. Axial dynamization and loading was individualized. Early dynamization was allowed only in transverse or short oblique fractures. Generally, partial weight bearing was allowed within 6 weeks and full weight bearing within 3 months. Each patient was evaluated clinically and radiographically at 1 month postoperatively and subsequently every month.
Fracture healing was assessed by standard radiographic projections and union defined as dense callus bringing at least three cortices. After radiographic confirmation of union, the device was removed with the pins left in place and the patients were instructed to fully bear weight. If there were no symptoms or pain, the pins were removed after 4 days. Range of movement of the knee and ankle were measured at that stage.

\section{Results}

We analyzed the medical records of the 212 patients admitted to the authors' institute. Three elderly patients died due to pulmonary embolism before fracture union and were excluded from the study. The average follow-up was 2.9 years (range $1-5$ years). The mean operative time was 35 min (time for irrigation and soft tissue debridement was not included). Six criteria were used to evaluate the results of treatment.

Time to union

Normal healing was defined as union within 6 months, delayed union as healing between 6 and 8 months, and nonunion as the absence of healing after 8 months. Mean time to fracture union for the 139 open fractures that did not required a change of fixation method or bone graft was 25 weeks (ranged 17-32, median time 28); in the 84 closed fractures this was 21 weeks (ranged 14-31, mean time 23) (Figs. 1, 2, 3; Table 1). Primary bone healing occured in 10 fractures and was due to the stiffness of the external fixators (Fig. 4). There were 18 nonunions and 21 delayed unions.
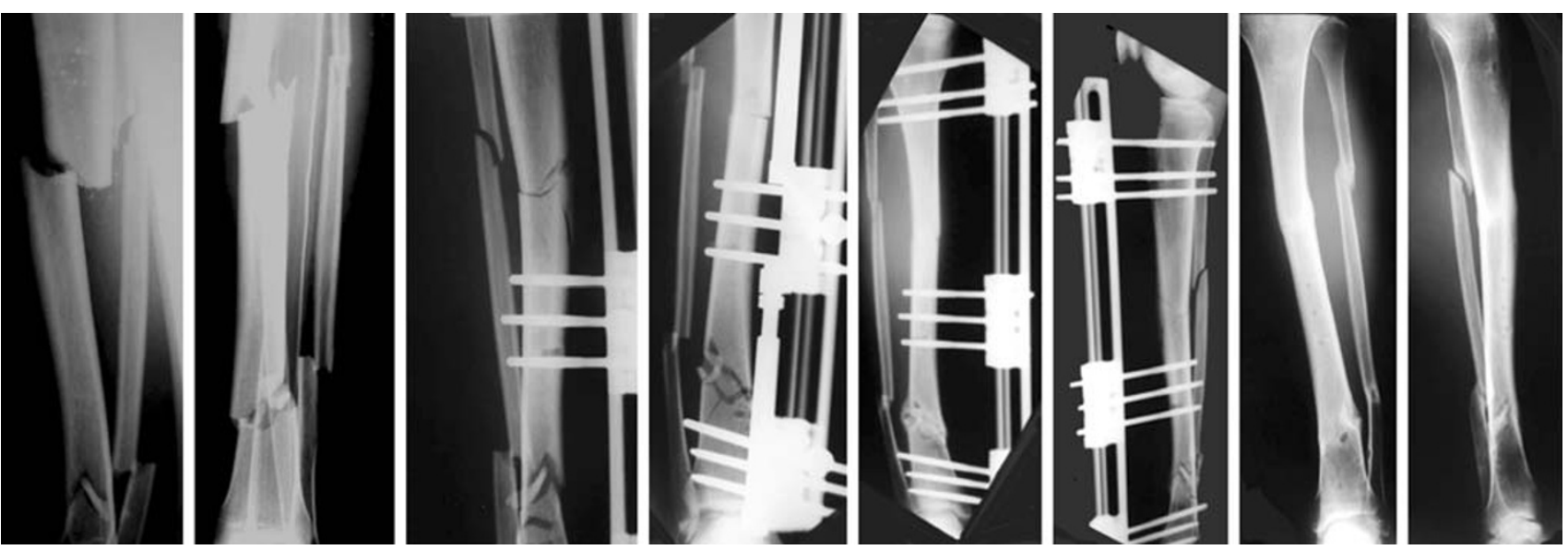

Fig. 1 A 45-year-old man with segmental fracture of the left tibia with severe soft tissue injuries that was managed with unilateral external fixator. Anteroposterior and lateral radiographs of the tibia.
External fixator was used for fracture stabilization. Postoperative radiographs (AP and lateral views). Plain radiographs of the tibia 24 weeks postoperative showed fracture union 

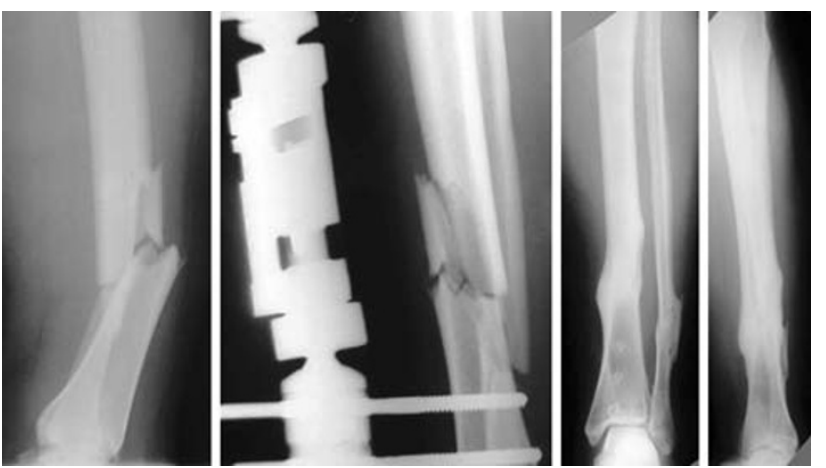

Fig. 2 Tibia shaft fracture in multiple injured patient with head injury. Stabilization of the fracture was achieved with unilateral external fixator. Plain radiographs 14 weeks postoperative showed fracture union with marked callus formation

\section{Final alignment}

A malunion was defined as varus or valgus malalignment of $5^{\circ}$ or more, anterior or posterior angulation of $10^{\circ}$ or more, shortening of $1 \mathrm{~cm}$ or more, or rotational malalignment of $10^{\circ}$ or more as compared with the contralateral leg. At the latest follow-up there were 4 malunions with tibial shortening and one hypertrophic nonunion with shortening of between 1.5 and $2 \mathrm{~cm}$.

Pin track infection and deep infection

Pin track infection is an inherent problem in external fixation. There were 58 pin track infections. There were three cases of osteomyelitis, but all in open fractures. Forty-three pin infections were managed successfully with antibiotics, while in 15 (7 patients) the pin had to be replaced. In the three cases of osteomyelitis, intravenous antibiotic treatment was combined with debridement of all necrotic tissue. All infections eventually resolved.
Table 1 Mean and Median time (weeks) of fracture union in 139 open fracture and 84 closed fractures that they did not reoperated

\begin{tabular}{lll}
\hline Fracture union & \multicolumn{2}{l}{ Time of treatment in weeks } \\
\cline { 2 - 3 } & Mean & Median \\
\hline 139 open & 25 & 28 \\
84 open & 21 & 13 \\
\hline
\end{tabular}

Final ranges of motion of the knee and ankle joint and pain

There was no restriction to motion of the knee and ankle joint and no patient complained of pain at the latest follow-up.

\section{Reoperations}

Severe open tibial fractures often require repeat procedures in the form of soft-tissue cover, bone grafting, or exchange nailing in order to achieve union. All procedures that necessitated general or spinal anesthesia and were directly related to treatment of the tibial fracture were included. Reoperation was performed in 42 fractures. The causes for reoperation were 18 nonunions, 10 out of 21 delayed unions, 3 with osteomyelitis, 4 malunions and 7 half pin revisions due to infection or loosening (Table 2), we changed the primary fixation device: 1 device was broken; 10 devices with adjustable joints within the pin clamps were changed to non-adjustable types with intention to allow axial interfragmentary compression. We also used bone graft for seven delayed unions. In 11 cases (3 osteomyelitis, 4 malunions and 4 nonunions -5 of them with shortening; 4 malunions and one nonunion) we changed the device to an Ilizarov circular frame; in 6 nonunion cases we used an intramedullary nail and, for 7 cases, we changed only 1 or 2 half-pins (Table 3). In all the above cases (except those where a change of half pins only was performed) an osteotomy of the fibula was performed. In total we changed the method or
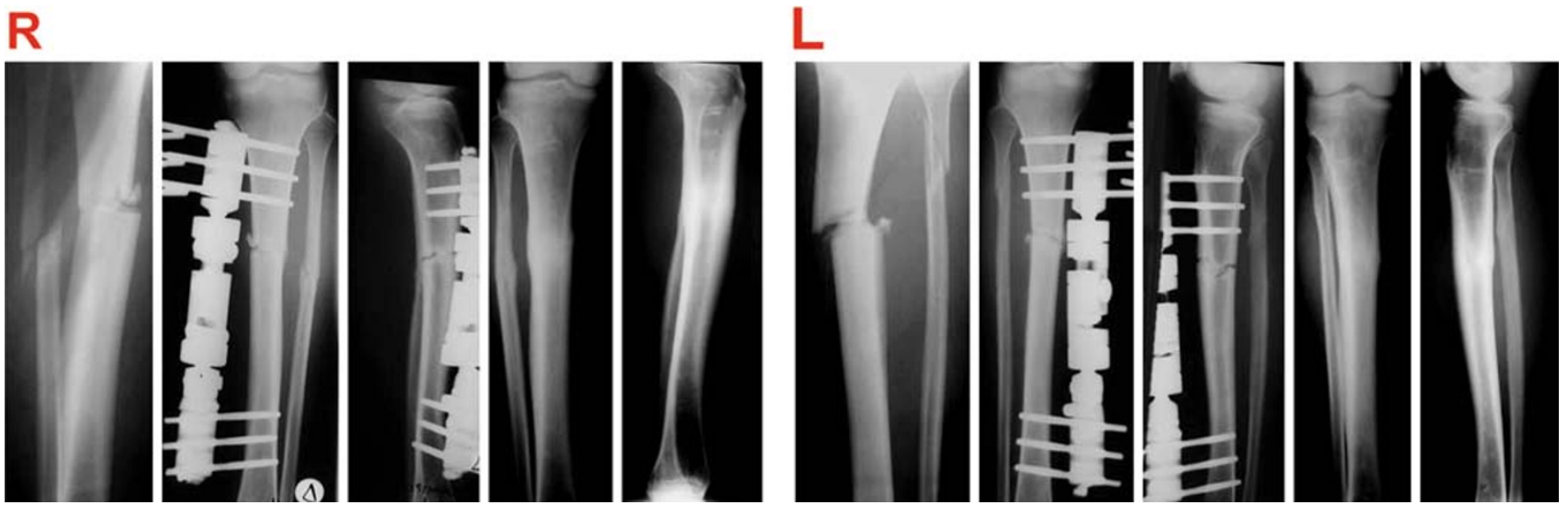

Fig. 3 Plain radiographs of both tibia (right and left) in a 36-year-old man. Unilateral external fixators were used to stabilize the tibia fractures. Plain radiographs (anteroposterior and lateral) 16 weeks postoperative showed fracture union 
Fig. 4 Open grade III tibia shaft fracture. Anteroposterior and lateral postoperative radiographs. Fracture union was achieved 20 weeks postoperatively. Primary callus formation was noticed (arrow)
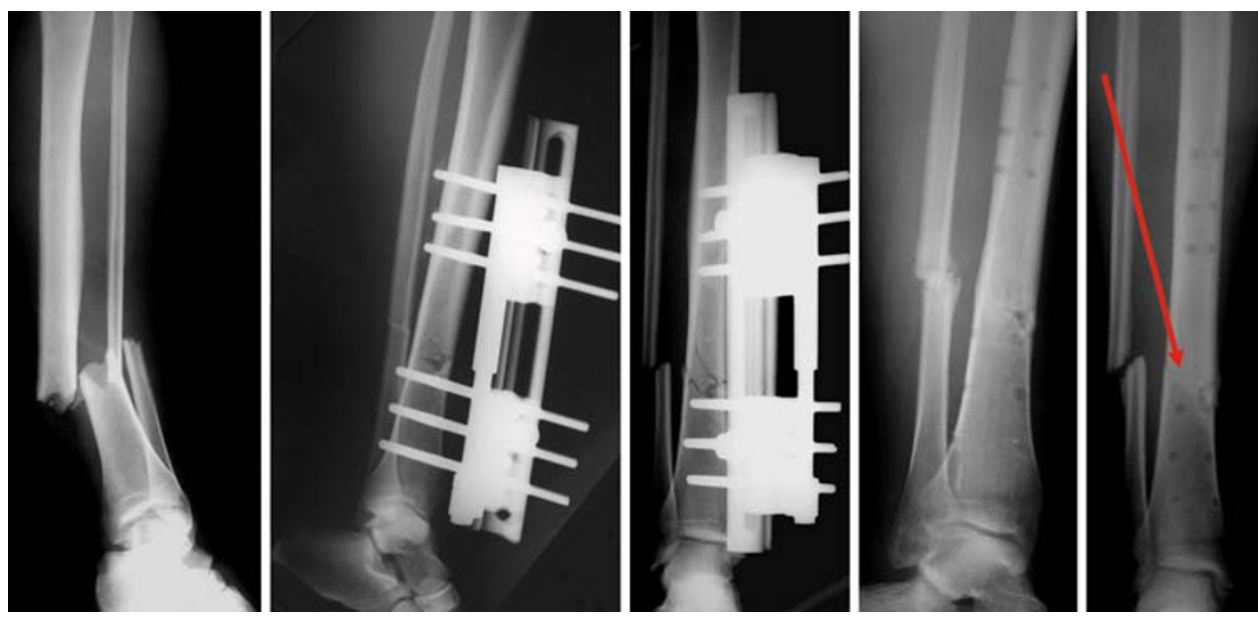

Table 2 Reoperations were performed in 18 nonunion, 10 delayed union, 3 osteomyelitis, 4 malunion and in 7 cases with pin infection or loosening

\begin{tabular}{llllll}
\hline Reoperations & & & & \\
\hline Diagnosis & Nonunion & Delayed union & Osteomyelitis & Malunion & Pin infection, or loosening \\
\hline No of fractures & 18 & 10 & 3 & 4 & 7 \\
\hline
\end{tabular}

Table 3 In 11 fractures we changed the device to a different one (1 device was broken and 10 jointed devices, all were changed in non jointed type) and we also used bone graft

\begin{tabular}{|c|c|c|c|c|c|}
\hline Type of reoperations & $\begin{array}{l}\text { Change of the device to } \\
\text { nonjointed plus bone graft }\end{array}$ & Only bone graft & Ilizarov circular frame & $\begin{array}{l}\text { Intramedullary } \\
\text { nail }\end{array}$ & Change 1 or 2 pins \\
\hline $\begin{array}{l}\text { Diagnosis } \\
\text { (no of fractures) }\end{array}$ & $\begin{array}{l}\text { Nonunion ( } 8 \text { cases) } \\
\text { delayed union }(3 \text { cases) }\end{array}$ & $\begin{array}{l}\text { Delayed union } \\
\text { ( } 7 \text { cases })\end{array}$ & $\begin{array}{c}\text { Osteomyelitis ( } 3 \text { cases) } \\
\text { malunion }(4 \text { cases }) \\
\text { nonunion }(4 \text { cases })\end{array}$ & $\begin{array}{l}\text { Nonunion } \\
\text { (6 cases })\end{array}$ & 7 cases \\
\hline
\end{tabular}

In 7 delayed unions we used only bone graft. In 11 cases we changed the device to an Ilizarov circular frame, in 6 nonunion cases to intramedullary nail and in 7 cases we changed only 1 or 2 pins

fixation device in 28 fractures $(12.72 \%)$. All the above reoperated fractures united in a mean time of 2.5 months (range $2-4$, median time 3 months).

Other complications

In three young patients fat embolism was diagnosed, while pulmonary embolism was a complication in five patients (three died). Deep venous thrombosis (DVT) based on clinical examination was suspected in 39 patients but confirmed by a Doppler ultrasonography examination in 14 patients only.

\section{Discussion}

Despite improvements in surgical techniques in the last century, the optimum treatment for open type III tibial shaft fractures, fracture with severe soft tissues injuries, threatened compartment syndrome, and tibial fractures in multiply injured patients remains controversial and major problems with infection, malunion and nonunion have persisted [1]. Although it is widely accepted that emergency irrigation and soft-tissue debridement are the cornerstones of initial care for open fractures, there is no consensus on the best method of obtaining and maintaining alignment and stability of the tibia. Intramedullary nails (IM), external fixation, external fixation followed by IM nailing, and plates have been proposed with, at times, less than optimal results [2-6].

In recent years, there has been increased interest in managing open fractures, even type IIIB, with reamed or unreamed nails [7]. In the belief that immediate intramedullary nailing increases the risk of septic complications, nonunion and pulmonary dysfunction, a sequence in management using external fixation initially and then 
delayed reamed IM nailing have been advocated-particularly for the treatment of type-III open fractures and in polytrauma patients $[8,9]$. The initial application of external fixation in open fractures followed by exchange to an IM nail has proponents and detractors to the technique [10-12]. Unfortunately, the risk factors leading to infection and nonunion when managing these types of fractures with this sequence of fixation are not well defined and the question on the best time to convert an external fixator to an IM nail remains unanswered [13, 14]. The major concern is to define an appropriate time interval between the removal of the pins and nailing which will allow for the host's defense mechanisms to eradicate any residual bacteria from the pin sites. In a recent systematic review of 96 open tibial fractures which were treated by external fixation followed by reamed IM nailing, union was achieved in $92 \%$ at a mean time of 38.5 weeks. The mean time of conversion from external fixation to reamed IM nailing was 26 days, always after complete healing of the pin track and with a normal ESR. Despite this policy, the overall rate of deep infection was $17 \%$, with $2.5 \%$ of cases developing chronic osteomyelitis [4].

In comparison, the information currently available concerning locking (angle-stable) plates is inadequate to enable a firm conclusion but, provided that appropriate soft tissue procedures are carried out early by experienced plastic surgeons, the results of plating are encouraging $[2,15]$.

External fixation has seen renewal in modern trauma management and new articles have appeared in the literature concerning the military use of external fixation in multiply injured or for the control of soft tissue problems in casualties of war (Croatia 1991,1992, Iraq 2003) [14, 16, 17]. Several reports of patients treated only by external fixation have been published with different and conflicting results [4, 18-20]. Compared with intramedullary nailing, external fixation is associated with a higher incidence of nonunion, malunion, and reoperations. Recently a metaanalysis of randomized prospective studies was performed directly comparing external fixators and unreamed IM nails. There was no statistically significant difference between the two methods of stabilization with respect to union, delayed union, deep infection and chronic osteomyelitis. The use of external fixation was associated with a statistically significant increased rate of malunion and further surgery, whereas unreamed nailing showed a statistically significant increase in the rate of failure of the implant [4]. Bhandari et al. carried out an indirect comparison between reamed intramedullary nails and external fixators from several prospective randomized studies that compared external fixation with reamed and unreamed IM nails. They concluded that use of reamed nails significantly reduced the risk of re-operation when compared with external fixators but not that of deep infection or nonunion
[3]. In our study, the incidence of nonunion and delayed union was 8.18 and $9.54 \%$, respectively. These are lower than those published currently in the literature. Kimmel [21] noted a $13 \%$ non-union and $39 \%$ delayed union rate when he reviewed open tibial fractures that were treated with external fixation. Velazco and Fleming [22], in a report on 40 open tibial fractures, noted a $12.5 \%$ incidence of delayed union. In the systematic analysis by Giannoudis et al., a total of 536 open tibial fractures were treated by external fixation of which $82 \%$ were grade-III open injuries. The overall incidence of delayed union (after six months) was $24 \%$ [4]. In the current study, the rate of malunion was $1.8 \%$ while in 5 tibia $(2.27 \%)$ there was more than $1.5 \mathrm{~cm}$ shortening that did not cause a significant disability. Kimmel [21] and Giannoudis et al. [4] have found a 26 and $20 \%$ rate of malunion, respectively. This difference may be explained by the effort of the authors to achieve an anatomic reduction. The incidence of pin track infection in this series was $26.36 \%$ whereas osteomyelitis developed in three open fractures $(1.36 \%)$. In the current literature, the incidence of pin track infection ranges from 32 to $80 \%$ while the incidence of deep infection is $16.2 \%$, with average $4 \%$ developing chronic osteomyelitis $[4,21$, 22]. The rate of total number of re-operations in our study was $19.09 \%$ with a change of the method or fixation device necessary in 28 fractures $(12.72 \%)$. The unilateral external fixator was definitive treatment in 192 out of 220 fractures $(87.27 \%)$ in this series. Velazco and Fleming noted a $2.4 \%$ reoperation rate [22] whereas in a recent analysis $68.5 \%$ of the fractures required at least one further operation before union was achieved [4]. In our study bone graft was used in six cases $(2.72 \%)$ while the published incidence of bone grafting is $45 \%$ currently $[4,21]$. This may be due to exclusion of all open fractures with bone loss in this series. Nevertheless, our results with external fixators are better than the results from previous studies in most respects. This may be explained by the inherent stability of the device we used (a rigid side bar), allowing for dynamization of the fracture, the operative technique, adherence to basic surgical principles and an effort to achieve an anatomical reduction including axial and side-to-side compression. With regard to the quality of fracture reduction, uniplanar devices with a rigid side bar are usually more difficult to adjust and the surgeon must take care to ensure a satisfactory reduction before the external fixator is applied. A good initial reduction is important no matter what type of fixator is applied, as it is often surprisingly difficult to achieve a secondary reduction if the primary reduction is unsuccessful. Moreover, the frame should be maintained long enough to prevent secondary loss of fracture reduction. Helland et al. [23] noted a significantly faster healing time in patients with exact reductions compared with fractures with greater than $2 \mathrm{~mm}$ translational displacement. 
Traditionally, external fixator half-pins are of stainless steel which is substantially stiff. Among the many different techniques to enhance fixation at the pin-bone interface, hydroxyapatite (HA) coating of the pins has been shown to be one of the most effective. The HA coating provides a significant increase in direct bone apposition with a decrease in the fibrous tissue interposition at the pin-bone interface. Moroni et al. [24] showed that HA-coated tapered pins improved the strength of fixation at the pinbone interface, which corresponded to a lower rate of pin tract infection. HA coating, owing to the increase in purchase at the pin-bone interface, may make extracting these pins more difficult or painful if without anesthesia. Despite not using HA half-pins, we encountered only three cases of osteomyelitis.

Movement across a fracture site induces callus formation and promotes healing. External fixation is the only treatment modality in which such cyclical movement can be controlled with dynamization. Klein et al., after mechanical and histomorphometrical observations, noticed significantly inferior bone healing in the IM nail group compared to the external fixator group. In their study, unreamed IM nailing of a tibial diastasis resulted in a significant delay in bone healing [25]. External fixators can be applied quickly; they provide fracture stability and alignment with minimal physiologic insult, there is no metal implant across the fracture site, and there is less vascular damage in a tibia that may already be compromised, particularly with some types of tibial shaft fractures. Another advantage of external fixators is that a second operation for removal of the device is not needed, with implications for cost effectiveness and patients' morbidity.

The retrospective nature of this study is a relative weakness but is offset by the large number of patients. This analysis provides another facet of information to trauma surgeon managing tibia shaft fractures.

Unilateral external fixators can be used as primary and definitive treatment for tibia shaft fractures and are associated with a low deep infection rate. Re-operation or a change of the method or fixation device should be performed only when there is a delay in callus formation. Advances in the design of fixators and bone pins may have expanded indications and their use as definitive fracture treatment and this may be a real alternative for trauma surgeons.

\section{References}

1. Matter P, Rittmann WW (1978) The open fracture: assessment, surgical treatment and results. Berne Year Book Medical Publishers, Chicago
2. Bach AW, Hansen ST Jr (1989) Plates versus external fixation in severe open tibial shaft fractures: a randomized trial. Clin Orthop Relat Res 241:89-94

3. Bhandari M, Guyatt GH, Swiontkowski MF, Schemitsch EH (2001) Treatment of open fractures of the shaft of the tibia: a systematic overview and meta-analysis. J Bone Joint Surg Br 83-B:62-68

4. Giannoudis P, Roberts C, Papakostidis C (2006) A review of the management of open fractures of the tibia and femur. J Bone Joint Surg Br 88-B:281-289

5. Huljev D, Rasic Z, Ivanusic M et al (1992) External fixation of war injuries. Ortop Traumatol 2-3(23):95

6. Milenkovi S, Mitkovi M, Radenkovi M (2005) External skeletal fixation of the tibial shaft fractures. Vojnosanit Pregl 62(1): $11-15$

7. Tornetta P III, Bergman M, Watnik N, Berkowitz G, Steuer J (1994) Treatment of grade-IIIB open tibial fractures: a prospective randomised comparison of external fixation and non-reamed locked nailing. J Bone Joint Surg Br 76-B:13-19

8. Chapman MW (1986) The role of intramedullary fixation in open fractures. Clin Orthop Relat Res 212:26-34

9. Giannoudis PV (2003) Surgical priorities in damage control orthopaedics. J Bone Joint Surg Br 85-B:478-483

10. Bhandari M, Zlowodzki M, Tornetta P, Schmidt A, Templeman DC (2005) Intramedullary nailing following external fixation in femoral and tibial shaft fractures. J Orthop Trauma 19(2): 140-144

11. Blachut PA, Meek RN, O'Brien PJ (1990) External fixation and delayed intramedullary nailing of open fractures of the tibial shaft: a sequential protocol. J Bone Joint Surg [Am] 72-A:729735

12. Malik ZU, Hanif MS, Safdar A, Masood T (2005) Planned external fixation to locked intramedullary nailing conversion for open fractures of shaft of femur and tibia. J Coll Physicians Surg Pak 15(3):133-136

13. Della Rocca GJ, Crist BD (2006) External fixation versus conversion to intramedullary nailing for definitive management of closed fractures of the femoral and tibial shaft. J Am Acad Orthop Surg 14(10):131-135

14. Dougherty PJ, Silverton C, Yeni DY, Tashman S, Weir R (2006) Conversion from temporary external fixation to definitive fixation: shaft fractures. J Am Acad Orthop Surg 14:124-127

15. Gopal S, Majumder S, Batchelor AG, Knight SL, De Boer P, Smith RM (2000) Fix and flap: the radical orthopaedic and plastic treatment of severe open fractures of the tibia. J Bone Joint Surg Br 82-B:959-966

16. Has B, Jovanovic S, Wertheimer B, Mikolasevic I, Grdic P (1995) External fixation as a primary and definitive treatment of open limb fractures. Injury 26:245-248

17. Haidukewych $G$ (2002) Temporary external fixation for the management of complex intra- and periarticular fractures of the, lower extremity. J Orthop Trauma 16:678-685

18. Braten M, Helland P, Grontvedt T, Aamodt A, Benum P, Molster A (2005) External fixation versus locked intramedullary nailing in tibial shaft fractures: a prospective, randomized study of 78 patients. Arch Orthop Trauma Surg 125:21-26

19. Reis ND, Zinman C, Besser MI, Shifrin LZ, Rosen H (1991) A philosophy of limb salvage in war: use of the fixateur externe. Mil Med 156:505-520

20. Rommens P, Broos P, Gruwez JA (1986) External fixation of tibial shaft fractures with severe soft tissue injuries by Hoffmann-Vidal-Adrey osteotaxis. Arch Orthop Trauma Surg 105(3): 170-174

21. Kimmel RB (1982) Results of treatment using the Hoffmann external fixator for fractures of the tibial diaphysis. J Trauma 22:960-965 
22. Velazco A, Fleming LL (1983) Open fractures of the tibia treated by the Hoffmann external fixator. Clin Orthop Relat Res 180: $125-132$

23. Helland P, Boe A, Molster AO, Solheim E, Hordvik M (1996) Open tibial fractures treated with the Ex-fi-re external fixation system. Clin Orthop Relat Res 326:209-220

24. Moroni A, Heikkila J, Magyar G et al (2001) Fixation strength and pin tract infection of hydroxyapatite-coated tapered pins. Clin Orthop 388:209-217
25. Klein P, Opitz M, Schell H, Taylor WR, Heller MO, Kassi JP, Kandziora F, Duda GN (2004) Comparison of unreamed nailing and external fixation of tibial diastases-mechanical conditions during healing and biological outcome. J Orthop Res 22(5):10721078 